\title{
Web Localization of Spanish SMEs: The Case of Study in Chemical Sector
}

\author{
Juncal Gutiérrez-Artacho ${ }^{1 *}$, María-Dolores Olvera-Lobo² \\ ${ }^{1}$ Department of Translation and Interpreting, University of Granada, SPAIN \\ ${ }^{2}$ Department of Information and Communication, University of Granada, SPAIN
}

*Corresponding Author: juncalgutierrez@ugr.es

Citation: Gutiérrez-Artacho, J. and Olvera-Lobo, M.-D. (2017). Web Localization of Spanish SMEs: The Case of Study in Chemical Sector. Journal of Information Systems Engineering \& Management, 2(3), 15. doi: $10.20897 /$ jisem. 201715

Published: August 2, 2017

\begin{abstract}
Constant changes in the economic environment, where globalization and the development of the knowledge economy act as drivers, are systematically pushing companies towards the challenge of accessing external markets. Web localization constitutes a new field of study and professional intervention. From the translation perspective, localization equates to the website being adjusted to the typological, discursive and genre conventions of the target culture, adapting that website to a different language and culture. This entails much more than simply translating the content of the pages. The content of a webpage is made up of text, images and other multimedia elements, all of which have to be translated and subjected to cultural adaptation. A case study has been carried out to analyze the current presence of localization within Spanish SMEs from the chemical sector. Two types of indicator have been established for evaluating the sample: indicators for evaluating company websites (with a Likert scale from 0-4) and indicators for evaluating web localization (0-2 scale). The results show overall website quality is acceptable (2.5 points out of 4$)$. The higher rating has been obtained by the system quality (with 2.9), followed by information quality (2.7 points) and, lastly, service quality (1.9 points). In the web localization evaluation, the contact information aspects obtain 1.4 points, the visual aspect 1.04, and the navigation aspect was the worse considered (0.37). These types of analysis facilitate the establishment of practical recommendations aimed at SMEs in order to increase their international presence through the localization of their websites.
\end{abstract}

Keywords: web localization, enterprises, internationalization, Spanish SMEs, chemical sector

\section{INTRODUCTION}

Localization forms part of the group of interdependent processes known by the acronym GILT: Globalization, Internationalization, Localization, Translation (Cadieux and Esselink, 2004). Observed individually it can be established that translation is a process by which the meaning of a written text in a source language is communicated through an equivalent text in the target language. Regarding localization, the most popular definition, put forward by the now disappeared Localization Industry Standard Association (LISA), maintains that this activity involves taking a product and making it linguistically and culturally appropriate for a locale, that is, the country and target language in which the specific product will be used and sold (LISA, 2003). LISA states that in the localization process the linguistic, content/cultural, physical and technical issues are implicated. Therefore, the languages involved must be taken into account, but also the currencies, symbols or culture, transferring the message to another linguistic and culturally different public. In fact, culture adaptation in software products or web text is one of the most important localization factors (Lommel, 2007). 
Internationalization is an attempt to give visibility to the information contained by the company. It has the objective of focusing on the development stage of a product that does not depend on the language that determines. The "internationalized text" is a beginning for localizations into the maximum number of languages possible (Pym, 2004). Thus, internationalization consists in identifying all local information that appears on a website, that is, that information that is dictated by the language and culture of the country where it was originally designed, for example, dates, numbers, currency, contact information, among others. These elements must be isolated and saved independently so they can be adapted to the specifications of any language.

Lastly, globalization combines the processes of internationalization and localization. It consists of the design of websites that can be used in different countries with a minimum of changes. It is a concept that belongs more to the marketing than the technical department. At present, globalization takes in processes broader than localization, facilitating product distribution or multilingual help to clients (Jiménez Crespo, 2008).

Beside the localization of software, videogames and apps, amongst others, in the last few years we have witnessed the unprecedented growth of web localization, a communicative, technological, textual and cognitive process by which interactive digital texts (or websites) are modified for use by an international public which is not the use initially foreseen (Jiménez Crespo, 2013). The localization of web content includes several sub-processes take place whose nature differs according to the context or intention. Different professional profiles intervene in the translation-localization process.

Translation professionals make up one of the basic axes of inter-linguistic mediation (Olvera-Lobo et al, 2005). Professional translation environments might currently be ruled by conflict, opacity and mistrust between translators and direct clients or managers, due to the computer-mediated nature of communication and of translation production networks (Abdallah and Kosniken, 2005; Alonso, 2016). Web localization is often the last stage before content is published (Herrmann and Sachse, 2007) and, depending on the process, it may happen that localizers do not have the freedom or the possibility to make the changes necessary to adequately adapt the content to their markets (de la Cova, 2016; Ferrás et al., 2017; Gutiérrez-Artacho and Olvera-Lobo, 2017a).

The interaction and collaboration of the translator-localizer team with other professionals should be sought, constituting an extensive group of different professionals (Olvera-Lobo and Gutiérrez-Artacho, 2017a, 2017c). Every step in the localization process is taken and decisions are made in accordance with the coordination of an extensive team work. The team members may include a project manager, desktop publisher, localization engineer, graphic designer, and technical expert to translator in action, linguists and other senior translators to revise the localization project (Odacioglu, 2015).

From a translation perspective, localization would be the equivalent of a website adjusting to the typological, discussion and gender conventions specific to the target language, adapting the website in question to a different language and culture. This means much more than simply translating the content of the pages. The content of a web page is made up of text images and other multimedia elements, all of which need to be translated and subject to cultural adaptation. Users should never notice that the site was originally created in another language. Additionally, commercial and business translation has a number of particularities that must necessarily be studied and taken into account in order to achieve the desired communication aims (Zhu, 2015a, 2015b).

The success of websites as global communication platforms, the exchange of information or the selling of products and services has been pronounced in the development of localization processes, closing the gap between Internet users from different socio-cultural and linguistic contexts. The economic importance of this phenomenon is increasing, and its significance is borne out by the growing body of research dedicated to localization, specialized conferences and the number of institutions offering training courses for professionals in this area.

The internationalization and localization of websites are complex and costly processes, to which many businesses are reluctant to implement them. The long-term benefits, however, far outweigh initial costs as they suppose the creation of new markets, an increase in sales, a simplification of the process of updating information and a greater speed in entering new markets, amongst other advantages (Corte, 2002). Web localization is essential for businesses for promotion in different markets. For example, one product that is going to be sold in Hungary is different to one in South American countries because there are totally different terms or symbols which could offend due to a different concept of a word, image or colour. The web localization process is understood as an adaptation procedure.

For this reason, it is said that websites, more than being translated, are localized, because they are translated to a language but adapted to everything else. This contemplates almost a need for survival on the part of companies. Internet visibility is not the sole factor but it is a very relevant one.

In this study, we have several starting hypotheses:

H1: Web localization is a tool still scarcely used by SMEs

H2: The location of corporate websites of SMEs is not being carried out properly

H3: The existence of guidelines, protocols and tools of advice and guidance contributes to facilitating and improving the work of the localization specialists who come from the field of translation. 
In this sense, this study contributes to analyze the quality of corporate websites -in the chemical sector, in this case -. In addition, the analysis contributes to determine the quality of the web location of the corporate websites in the Spanish SMEs context, that are strategic for the whole of the Spanish economy and its regions.

\section{SMEs ON THE WEB: THE CASE OF SPAIN}

The Strategic Plan for Internationalization and Priority Markets (2014-2015) elaborated every two years by the Spanish Ministry of Economy and Competitiveness, within the Inter-ministry Group for Support for the Internationalization of Spanish Businesses, and with the participation of the private sector and the Autonomous Regions, has the main objective of driving the internationalization of the Spanish economy, improving its competitiveness and favouring the global presence of Spanish businesses, thus contributing to the implementation of a new model of economic growth for Spain orientated towards the exterior. Nevertheless, in relation to ecommerce and its online presence, Spanish companies still have a long way to go. In accordance with a recent report carried out by the Nominalia hosting company (www.nominalia.com) in 2015, 36.20\% of Spanish companies still lack a corporate website, although $22.41 \%$ are in possession of one or more domains while awaiting the creation of their website. Interestingly, the same study reveals how $89.6 \%$ of users consider it essential for a company to have a web presence, even if it is just for questions of image and trustworthiness. Another report carried out by the Nominalia hosting company in 2016 confirms that only $35.20 \%$ of Spanish companies make SEO process, in spite of that $45.40 \%$ of consulted Spanish companies state the major benefit that a website can be provided to the companies is the visibility.

Small and medium-sized enterprises (SMEs) are especially vulnerable in this changing environment. The microenterprises and SMEs are the motor of European Economy, since they promote job creation and economic growth, as well as ensuring social stability. In 2013, more than 21 million SMEs provided 88.8 million of jobs throughout the European Union (EU) (European Commission, 2015). The category of SMEs is defined by the European Commission as having less than 250 persons employed. They should also have an annual turnover of up to EUR 50 million, or a balance sheet total of no more than EUR 43 million (European Commission, 2014).

In 2016, 99.70\% of Spanish companies (SMEs and large companies) had technical access to the Web (ONTSI, 2015). However, the online presence through a corporate website reached $76.7 \%$ of the companies and this varied depending on their size and business sector. SMEs are conscious of the fact that, as well as having a presence on the internet, it must be frequently optimized and maintained. Today, $57.30 \%$ of SMEs already had their own website in 2016 (EBAY, 2016). Any business without a website will not be found on one of the most powerful marketing tools available to it. A website affords credibility and, furthermore, helps to show the success of a company. In a website is also much easier to update information on its products and services than a printed brochure or catalogue. Thus, it is a good way to inform users of the new arrival of products, services, events, deals, etc. that can be offered to them.

One of the main challenge of SMEs is to improve web portals optimizing them for mobiles -only $26 \%$ of SMEs have services optimized for mobile devices (EBAY, 2016)-, SEO, making company videos or creating forums. Furthermore, companies with a social network presence enjoy a greater increase in sales. That is why $67.40 \%$ of SMEs consider that companies without a social network profile will be left behind technologically. In terms of the presence of the company on social networks, there has been a considerable increase over the last three years. The most accepted social network is Facebook.

Starting out from this reality and from the fact that the translation and localization of websites contribute towards promoting the launch towards foreign markets of Spanish SMEs, Web localization constitutes a new area of study.

On the other hand, according to the data of the Annual Spanish National Accounts, Chemical Industry is the third largest industrial sector of the Spanish economy. It reached 15.533 million Euros in 2014, representing $12.40 \%$ of the total added value from manufacturing industry. This data places Chemical Industry as the third largest industrial sector for its contribution to GDP, as the same that the metallurgical sector $(12.04 \%)$, and only behind food industry and transport and automobiles (FEIQUE, 2016).

Sales by the Spanish chemical sector totaled $€ 58,056$ million in 2015, a rise of $3 \%$ over 2014 and $16.70 \%$ since 2007 -the year that the crisis began- compared to a $24 \%$ contraction in sales recorded by Spain's combined industrial sectors. Foreign markets, which account for $56.50 \%$ of sales, were once again the main driver of growth in the sector, with exports increasing by $2.5 \%$ to $€ 32,774$ million compared to 2014 and $43.30 \%$ higher than in 2007 (FEIQUE, 2016).

The Spanish chemical sector, which consists of more than 4,014 companies -of which $96 \%$ are SMEscurrently generates 540,000 direct, indirect and induced jobs. In addition to strong export capabilities, its competitiveness also lies in its capacity for innovation and technology, accounting for $24.90 \%$ of all $\mathrm{R} \& \mathrm{D}+\mathrm{i}$ 
investments made by Spanish industry as a whole, and employing $21.10 \%$ of all research personnel in industrial companies (FEIQUE, 2016). These characteristics make it a strategic, competitive and international sector.

This study analyses the degree to which Spanish Chemical SMEs are implementing their web localization to guarantee their presence in other markets. The quality of e-commerce is not measured, rather simply the information about service and products they offer.

\section{METHODOLOGY}

A pilot study has been carried out to analyse the current presence of the web localization in chemical Spanish SMEs. The initial study sample included the spanish chemical sector SMEs which are award-winning in 2015, and those presents in the DMOZ directory.

The award-winning companies were recognised by FEIQUE (Business Federation of the Spanish Chemical Industry) in its 1st RSE (Corporate Social Responsibility) Awards, and by the DHL Atlas Export Awards 2015. FEIQUE, in collaboration with the Spanish Chemical Forum and Society, celebrated its $1^{\text {st }}$ RSE Awards in Chemical Sector. Its Awards recognized the engagement of 17 Chemical companies in the principles of Corporate Sustainability and Social Responsibility (FEIQUE, 2015). Also, the companies of the sample were selected from the 2015 DHL ATLAS Awards Edition. The winners were three SMEs but only one in the Chemical sector -it was awarded this prize for the innovation in its structure of services and solutions through biotechnology and analytical chemistry (DHL News, 2015).

We have selected mainly the Chemical companies in the recently disappeared DMOZ web directory ${ }^{1}$, also called Open Directory Project. It was the largest, most comprehensive human-edited directory of the Web. It was constructed and maintained by a global community of volunteer editors. These citizens could each organize a small portion of the web and present it back to the rest of the population, culling out bad content and adding just the best content. It could be considered as a relevant, reliable information source. DMOZ had a high page rank because Google had trust in the review of the editor. Google also believe that the websites listed on DMOZ was useful and informational. Therefore, site listed in DMOZ was given priority in most cases.

In the second phase of our selection we have used the search engine of the Spanish economic journal Expansion $^{2}$ to establish what companies selected in the first phase could be considered as a SME. Only two of the FEIQUE Awards and one of the DHL ATLAS Awards were selected as part of our sample. As indicated, the rest of SMEs selected to carry out the evaluation were obtained in the "Bussiness-Chemicals-Spain" category of DMOZ directory.

All of these companies had a size of between 50 and 249 employees and a turnover higher than $€ 50$ million. For the definitive sample selection, only the 31 SMEs with a website were selected.

Two types of indicator have been established for evaluating the sample: indicators for evaluating company websites and indicators for evaluating web localization.

The first ones focus on the quality of the websites. We have developed a checklist based on the methodology proposed by Chua et al. (2012). Chua and colleagues grouped its checklist into three dimensions: quality of the system, quality of the information, and quality of service. Quality of the system refers to the website functionality, made up of four indicators - ease of access, usability, capacity for response and design-. Quality of the information is related to the precision, reliability, coverage and ease of use. Finally, Quality of service measures the empathy, interactivity, site 'happiness' and aesthetic attractiveness.

The indicators (Table 1) have been evaluated with a Likert scale from 0-4: 0 (no indicator shown), 1 (shows indicator very poorly), 2 (shows indicator poorly), 3 (shows indicator well) and 4 (the indicator is shown very well).

The second type of indicators refers to web localization. In the web localization evaluation, translated text is as important as adaptation to the locale. In terms of web localization, $71 \%$ of SME websites of the sample are localized in another language. The criteria evaluation is based on three dimensions: visual level, navigational level and contact information level. They have been measured on a more reduced Likert scale of $0-2$, because they involve a more specific type of characteristic: 0 (no indicator, not evaluated), 1 (indicator, poor), 2 (indicator, good).

Related to visual level, the indicators evaluated are the text -if the text is totally localized and translated-, figures -if the figures, images, videos and tables has been also translated and localized-, segments -if the distribution of text's paragraphs has the same structure in the different localized languages-, updates -if news, blogs, press releases have also been localized-, languages -if the text and updates are made equally for all the languages in which the website is located-, homogeneity -if different sections of the website are localized or some of them not-, and

${ }^{1}$ DMOZ. Available in: http://www.dmoz.org/

${ }^{2}$ Expansión. Available in: http://www.expansion.com/empresas-de/buscadorEmpresas.html 
Table 1. Dimensions and indicators for evaluation

\begin{tabular}{|c|c|c|}
\hline \multirow{2}{*}{ Sample } & \multicolumn{2}{|c|}{31 SMEs of the chemical sector (awarded or presents in DMOZ Directory) } \\
\hline & Dimensions & Indicators \\
\hline \multirow{3}{*}{$\begin{array}{l}\text { Indicators for evaluating } \\
\text { companies' website } \\
\text { Likert scale (0-4) }\end{array}$} & Quality of system & $\begin{array}{l}\text { ease of access } \\
\text { usability } \\
\text { capacity for response } \\
\text { design }\end{array}$ \\
\hline & Quality of the information & $\begin{array}{l}\text { precision } \\
\text { reliability } \\
\text { coverage } \\
\text { ease of use }\end{array}$ \\
\hline & Quality of service & $\begin{array}{l}\text { empathy } \\
\text { interactivity } \\
\text { site 'happiness' } \\
\text { aesthetic attractiveness }\end{array}$ \\
\hline \multirow[t]{3}{*}{$\begin{array}{l}\text { Indicators for evaluating } \\
\text { web localization } \\
\text { Likert scale }(0-2)\end{array}$} & Visual level & $\begin{array}{l}\text { text } \\
\text { figures } \\
\text { segments } \\
\text { updates } \\
\text { languages } \\
\text { homogeneity } \\
\text { slogans }\end{array}$ \\
\hline & Navigational level & consistency in localization browsing \\
\hline & Contact information level & elements of contact and information about the company \\
\hline
\end{tabular}

slogans -the slogan of a company identifies and publicizes the services or products offered so it is important to take care of this aspect in the website localization.

The navigational level takes into account the consistency in localization browsing the entire website through the different sections. For its part, the contact information level takes into account whether all the elements of contact and information about the company (maps, addresses, telephone numbers, examples, legal information, etc.) have been adequately adapted.

\section{RESULTS}

In accordance with the result obtained, the overall quality of websites, with 2.5 points obtained, is above the average 2 of the Likert scale of 0 to 4 . The higher rating has been obtained by the system quality with 2.9, followed by information quality ( 2.7 points) and, lastly, service quality (1.9 points).

Respect to quality of system, in terms of ease of access, the websites have acceptable results on the basis of a search via the name of the company in question. As regards the definition of usability according to the ISO 9241 regulation, it can be said that the websites in the chemical sector are effective, efficient and satisfactory, with which a product can reach the specific objectives for determined users within the sector (3.2 points). The capacity for response was also correct (3.3 points), and the websites loaded quickly and provided navigation systems such as breadcrumbs, sitemaps, menu bars, etc. In relation to design, 39\% of SMEs in the sample use a technology that facilitates access from different devices such as mobile phones and tablets, amongst others. $71 \%$ employ RSS syndication technology that facilitates the notification of an update or publication of new information on the site.

The results of the case study reveal that, in terms of the first analysis carried out - evaluation of website quality, the quality of the system and the quality of the information have a average score acceptable on the websites in the sample. In contrast, the quality of service does not reach a minimum acceptable score. In this sense, particular attention may be drawn to social networks, which would form part of the interactivity indicator.

Under half of the companies are active on the social networks. A mere $48 \%$ of websites use them and of these, only $15 \%$ allow the creation and publication of opinions and content. The social networks that most stand out are Facebook, Twitter, YouTube, Blogger, Skype, Instagram, amongst others.

With these results, it is easy to think that Spanish SMEs pay little attention to the user. The websites analyzed frequently do not offer differentiated services for various user profiles, and the possible interactivity is very low within the website, amongst other aspects. It has also been demonstrated that in relation to design the large majority of SMEs websites do not present an option to access different devices such as tablets or mobiles. 


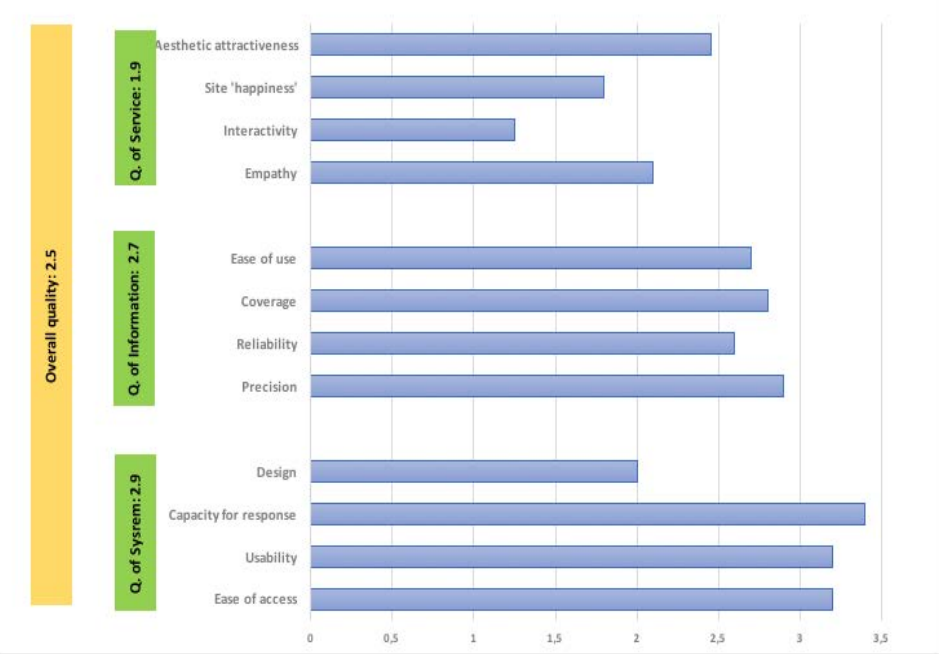

Figure 1. Results of website evaluation

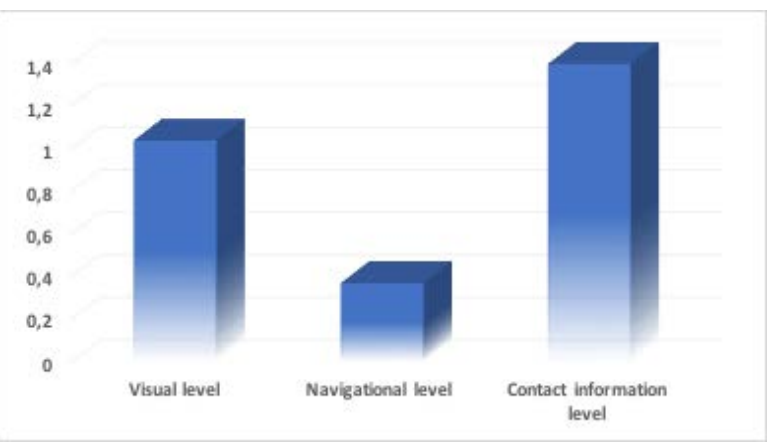

Figure 2. Results of website localization evaluation

The evaluation of web localization (0-2 scale) show that the contact information aspect has the best rating (1.4), which means that the companies adapt the telephone number, cookie policy and address, amongst other aspects.

The visual aspect, which had the greatest number of indicators assessed, obtained 1.04 score and, finally, the navigation aspect was the worse considered (0.37).

\section{CONCLUSIONS}

The continuous transformation in the economic environment, where the acceleration of the globalization process and development of the knowledge economy are driving forces is systematically pushing businesses towards the challenge that entering foreign markets poses (Gutiérrez-Artacho and Olvera-Lobo, 2017b). This study arises from this reality, and from the fact that the translation and localization of websites contributes to the internationalization of SMEs, closing the gap between Internet users from different socio-cultural and linguistic contexts. Our aim is to show the importance of localization for the facilitation and improvement of the processes of externalization and globalization of Spanish SMEs. It is essential to determine the most appropriate indicators in this context for measuring the quality of the localization of corporate SME websites from a technical and formal perspective, but also in terms of content (linguistic) (Olvera-Lobo and Gutiérrez-Artacho, 2017b).

In this scenario, upon analysing the usage and quality of the websites of SMEs from the chemical sector in Spain, we have observed that $61 \%$ of them do not have the technology necessary to correctly access the website from any mobile device. Furthermore, the growing use of such devices makes it necessary to adapt this web content to Smartphones, as it would lead to a growth in clients and users. In addition, following the analysis of these websites, we have detected that both the informative content and the tools are out-of-date and obsolete.

However, the SMEs that employ a more advanced use of their websites have been able to apply the advantages offered by web localization in another language, as this affords greater internationalization and globalization. The companies that have their websites localized in another language are more internationally visible and as a result their products can reach any location without the website being an inconvenience, as it is correctly translated. However, it would be convenient for the companies lacking this tool to increase the presence of personnel qualified 
within the sphere of web localization and in the use of Web 2.0 tools. Following the assessment we can see that many companies are making great efforts to improve the localization of their websites.

Website translation and localization help encourage small and medium-sized enterprises to internationalize, thereby closing the gap between internet users from different socio-cultural and linguistic contexts. For this reason, it is essential to make corporate website localization processes easier and better for SMEs, by providing a transdisciplinary and multidisciplinary perspective. The evaluation of the localization quality of the corporate websites of SMEs will also can facilitate the establishment of practical recommendations aimed at SMEs in order to increase their international presence through the localization of their websites.

As a final conclusion, it can be said that the survival of these companies in a globalized market is inextricably linked to the adaptation of informative content, as minimum, into a universal language such as English. These premises are key; they are needed from the point of view of information and communication for the survival of SMEs in international markets.

\section{ACKNOWLEDGMENT}

The authors are grateful to the Spanish "Ministry of Science and Innovation" for supporting this study, in the framework of the research Project CSO2015-64532-R, partially funded by the FEDER program of the European Union.

\section{REFERENCES}

Abdallah, K. and Koskinen, K. (2007). Managing trust: Translating and the network economy. Meta: Journal des Traducteurs / Meta: Translators' Journal, 52(4), pp. 673-687.

Alonso, E. (2016). Conflict, opacity and mistrust in the digital management of professional translation projects. The International Journal of Translation and Interpreting Research, 8(1), pp. 19-29.

Cadieux, P. and Esselink, B. (2004). GILT: Globalization, Internationalization, Localization, Translation. Globalization Insider, 11(1.5), pp. 1-5.

Chua, A., Goh, D. and Ang, R. (2012). Web 2.0 application in government web sites: Prevalecence use and correlotaions with perceived web site quality. Journal Information Review, pp. 175-195.

Corte, N. (2002). Localización e internacionalización de sitios web. Tradumática. 2002.

de la Cova, E. (2016). Translation Challenges in the Localization of Web Applications. Sendebar: Revista de la Facultad de Traducción e Interpretación, 27, pp. 235-266.

DHL News (2015). Premios DHL ATLAS a la exportación. Available at: http://www.premiosdhlatlas.com/\#anteriores

EBAY (2016). Guía práctica de E-Commerce. Available at: https://www.aceleraconebay.com/sites/default/files/Guide_SMB_ES_interactive_eBay.pdf

European Commission (2014). Reglamento (UE) n 651/2014 de la Comisión, de 17 de junio de 2014, por el que se declaran determinadas categorías de ayudas compatibles con el mercado interior en aplicación de los artículos 107 y 108 del Tratado. «DOUE» núm. 187, de 26 de junio de 2014, pp.1-78.

European Commission (2015). Dirección General de Mercado Interior, Industria, Emprendimiento y Pymes. Guía del usuario sobre la definición del concepto de pyme Luxemburgo: Oficina de Publicaciones de la Unión Europea.

FEIQUE - Federación Empresarial de la Industria Química Española (2015). Nota de prensa - FEIQUE hace entrega de sus I Premios RSE a 17 empresas del sector químico. Available at: http://www.feique.org/wpcontent/uploads/2017/02/12-10-NdP-Feique-entrega-sus-I-Premios-RSE-a-17-companias-del-sectorquimico.pdf

FEIQUE - Federación Empresarial de la Industria Química Española (2016). Radiografía Económica del Sector Químico Español. Available at: www.feique.org/pdfs/Radiografia_Economica_del_sector_2016.pdf

Ferrás, C., García, Y., Aguilera, A. and Rocha, Á. (2017). How Can Geography and Mobile Phones Contribute to Psychotherapy?. Journal of medical systems, 41(6), pp. 1-6.

Gutiérrez-Artacho, J. and Olvera-Lobo, M.D. (2017a). La opinión de los expertos sobre la formación en nuevos perfiles profesionales de la traducción: El método Delphi como herramienta. XV JORNADAS HISPANORUSAS DE TRADUCCIÓN E INTERPRETACIÓN. Universidad Estatal Lingüistica de Moscú. 14-15 de junio de 2017, Moscow (Rusia).

Gutiérrez-Artacho, J. and Olvera-Lobo, M.D. (2017b). Web localization as an essential factor in the internationalisation of companies: an approximation of Spanish SMEs. In: Á. Rocha, A. Correia, H. Adeli, L. 
Reis and S. Costanzo, ed., Recent Advances in Information Systems and Technologies, WorldCIST 2017, Advances in Intelligent Systems and Computing, vol 569, pp. 511-520. Springer, Cham.

Herrmann, A. and Sachse, F. (2007). Internacionalización de aplicaciones de software. In Detlef Reineke, ed., Traducción y localización. Mercado, gestión y tecnologías. 45-70. La Palmas de Gran Canaria: Anroart.

Jiménez Crespo, M.A. (2008). El proceso de localización web: estudio contrastivo de un corpus comparable del género sitio web corporativo. Granada: Universidad de Granada.

Jiménez Crespo, M.A. (2013). Translation and Web Localization. New York: Routledge.

LISA (2003). Localization Industry Primer. Geneva: Localization Industry Standards Association.

Lommel, A. (2007). The Globalization Industry Primer: An Introduction to preparing your business and products for success in international markets, pp. 70.

Odacioglu, M.C. (2015). From Interdisciplinarity to Transdisciplinarity in Translation Studies in the Context of Technological Tools \& Localization Industry. International Journal of Comparative Literature \& Translaton Studies, $3(3)$

Olvera-Lobo, M.D., Castro Prieto, M.R., Robinson, B., Quero, E., Muñoz Martín, R., Muñoz Raya, E., Murillo, M., Senso, J.A., Vargas, Domínguez-López, C. (2005). Translator Training and Modern Market Demands. Perspectives: Studies in Translatology, 13(20), pp. 132-142.

Olvera-Lobo, M.D. and Gutiérrez-Artacho, J. (2017a). Los procesos de enseñanza-aprendizaje de la traducción desde una perspectiva profesional e interdisciplinar: la localización web como nuevo mercado. In: $X V$ JORNADAS HISPANO-RUSAS DE TRADUCCIÓN E INTERPRETACIÓN. Universidad Estatal Lingüistica de Moscú. 14-15 june, Moscow (Rusia).

Olvera-Lobo, M.D and Gutiérrez-Artacho, J. (2017b). Web localization: the Spanish SMEs as case of study. In Information Systems and Technologies (CISTI), 2017 12th Iberian Conference on (pp. 1-5).

Olvera-Lobo, M.D. and Gutiérrez-Artacho, J. (2017c). Training versus profession: from traslation to web locatio. In: Proceedings of INTED2017 Conference, 6th-8th March 2017, Valencia (Spain), pp. 5461-5469.

ONTSI (2016). La sociedad en red. Informe anual 2015. Observatorio Nacional de las Telecomunicaciones y la Sociedad de la Información. Available at: http://www.ontsi.red.es/ontsi/

Pym, A. (2004). Localization from the Perpective of Translation Studies: Overlaps in the digital divide?. In: Conferencia SCALLA 2004.

Zhu, P. (2015a). On the Right Strategies for Translating Business \& Technical Information. Journal of Education and Social Science, 2(1), pp. 61-70.

Zhu, P. (2015b). Translation Criteria: How They May Affect International Business. Journal of Technical Writing and Communication, 45(3). 